\title{
A GÊNESE DO MITO: \\ A IDEIA DA EXCELÊNCIA E A CRIAÇÃO DO COLÉGIO UNIVERSITÁRIO DA UFV
}

\begin{tabular}{c} 
THE GENESIS OF MYTH: \\
THE IDEA OF EXCELLENCE AND THE FOUNDATION \\
OF UFV UNIVERSITY COLLEGE \\
\hline LA GÉNESIS DEL MITO: \\
LA IDEA DE LA EXCELENCIA Y LA CREACIÓN \\
DEL COLEGIO UNIVERSITARIO DE LA UFV
\end{tabular}

Joana D'Arc Germano Hollerbach ${ }^{1}$

RESUMO: Este artigo tem por objetivo discutir o processo de criação e consolidação do COLUNI - Colégio Universitário da Universidade Federal de Viçosa. O recorte estudado compreende o período entre 1965, quando o Colégio foi criado, e 1981, último ano em que ofertou apenas o terceiro ano do segundo grau. A pesquisa teve por método a pesquisa histórica, mediada pelo materialismo histórico dialético, pautada em fontes documentais primárias. A criação do COLUNI tinha por objetivo preparar os jovens candidatos aos cursos superiores da então Universidade Rural do Estado de Minas Gerais (UREMG), tendo em vista a defasagem acadêmica trazida por esses jovens do ensino secundário. A busca pela excelência no ensino superior era o mote que orientava a organização do Colégio, justificando sua existência mesmo depois da revogação do artigo 79, da Lei 4.024/61. Discutimos como a ideia de excelência acompanhou o primeiro período de existência do Colégio, a despeito das dificuldades encontradas nos primeiros anos.

PalavraS-Chave: Colégio Universitário. Ensino secundário. Elite.

ABSTRACT: This article aims to discuss the process of foundation and consolidation of COLUNI - University College of the Federal University of Viçosa. This study comprises the period between 1965, when the College was founded, and 1981, last year in which only the third year of secondary education was offered. This work had as a method the historical research, mediated by dialectical historical materialism, based on primary documentary sources. The fundation of COLUNI was aimed at preparing the young applicants for the higher courses in the Rural University of the State of Minas Gerais (UREMG), considering the academic disadvantage brought by these young students of high school. The search for excellence in higher education was the issue that guided the organization of the College, justifying its existence even after the revocation of article 79, Law $4.024 / 61$. This research proposes the discussion about how the idea of excellence accompanied the first period of existence of the College, despite the difficulties encountered in the early years.

KEYWORDS: University College. Secondary education. Elite.

RESUMEN: Este artículo tiene como objetivo discutir el proceso de creación y consolidación de COLUNI Colegio Universitario de la Universidad Federal de Viçosa. El recorte estudiado comprende el periodo entre 1965, cuando fue creado el Colegio, y 1981, último año en el que se ofertó solamente el tercer año de la secundaria. La investigación tuvo como método la investigación histórica, mediada por el materialismo histórico dialéctico, pautada en fuentes documentales primarias. La creación de COLUNI tenía como objetivo preparar a los jóvenes candidatos a los cursos superiores de, en la época, la Universidad Rural del Estado de Minas Gerais

\footnotetext{
${ }^{1}$ Submetido em: 09/03/2018 - Aceito em: 26/3/2018 - Publicado em: 17/01/2019
}

\begin{tabular}{l|c|c|c|c|c|c} 
(C) Rev. Educ. Perspec. & Viçosa, $M G$ & v.9 & n.3 & p.603-618 & set./dez.2018 & eISSN 2178-8359 \\
\hline
\end{tabular}


(UREMG), teniendo en cuenta el desfase académico traído por estos jóvenes de la enseñanza secundaria. La búsqueda por la excelencia en la enseñanza superior era la motivación que orientaba la organización del Colegio, justificando su existencia aun después de la revocación del artículo 79, de la Ley 4.024/61. Discutimos como la idea de la excelencia acompañó el primer periodo de existencia del Colegio, a pesar de las dificultades encontradas en los primeros años

PALABRAS CLAVE: Colegio Universitario. Enseñanza secundaria. Elite.

\section{INTRODUÇÃO}

Este artigo tem por objetivo compreender o processo de criação e consolidação do COLUNI Colégio Universitário da Universidade Federal de Viçosa (UFV). O recorte estudado compreende o período entre 1965, quando o Colégio foi criado, e 1981, último ano em que ofertou apenas o terceiro ano do então segundo grau.

O Colégio Universitário (COLUNI) da Universidade Federal de Viçosa foi criado em 1965, com base no $\S 3 .^{\circ}$, do artigo 79 da Lei 4.024/61:

A universidade pode instituir colégios universitários destinados a ministrar o ensino da $3^{\text {a }}$ (terceira) série do ciclo colegial. Do mesmo modo pode instituir colégios técnicos universitários quando nela exista curso superior em que sejam desenvolvidos os mesmos estudos. Nos concursos de habilitação não se fará qualquer distinção entre candidatos que tenham cursado êsses [sic] colégios e os que provenham de outros estabelecimentos de ensino médio ${ }^{i}$ (BRASIL, 1961).

A década de 1960 foi marcada pelas perspectivas de modernização política e econômica que buscavam romper com o passado agrário e conservador. Os movimentos anteriores de industrialização do país e de modernização do sistema educacional resultaram em mudanças pálidas no contexto nacional (FERREIRA JR., 2010). O baixo nível de escolarização da população e a predominância do modelo econômico agrário-exportador permaneceram até a década de 1960. Naquele período o país passava por um momento de efervescência política que culminou no golpe militar de 1964. Tínhamos, portanto, um cenário de profundas mudanças sociais e políticas no país.

A proposta de desenvolvimento para o país, que buscava alçar a nação a níveis de desenvolvimento superiores implicava numa nova ordem para a educação, adequando-a aos planos de desenvolvimento econômico. Sobre o desenvolvimento econômico, Ferreira Jr. (2010, p. 96) afirma que

Os governos militares adotaram um movimento político de duplo sentido: ao mesmo tempo em que suprimiam as liberdades democráticas e instituíam instrumentos jurídicos de caráter autoritário e repressivo, levaram à prática os mecanismos de modernização do Estado nacional no sentido de acelerar o processo de desenvolvimento do capitalismo brasileiro. 
O golpe de 1964 reforçou os laços da economia com o capital internacional, do que resultaram opções econômicas que, longe de reduzir a miséria e aumentar os níveis de acesso da população a condições de vida mais dignas, aumentaram a desigualdade social, aprofundando o abismo entre os que tinham e os que não tinham. Apesar da determinação de escolarização obrigatória para o nível primário longe de resolver o problema estrutural do analfabetismo, uma parcela significativa da população era mantida fora da escola. A proposta de criar os colégios universitários vinha, portanto, buscar paliativo para um problema grave que era a má formação de jovens candidatos ao ensino superior, dada a precária condição da educação nacional.

Oito anos depois da promulgação da Lei 4.024/61 (BRASIL, 1961), o Decreto-Lei no 464/69 (BRASIL, 1969), revogou o artigo 79 que autorizava a criação dos colégios universitários, no bojo da Reforma Universitária, proposta pelo governo militar. A ideia de criação de um ciclo básico de formação no ensino superior tinha por objetivo suprir essa lacuna e esvaziava a função dos colégios universitários, qual seja de recuperar a aprendizagem de jovens mal formados no ciclo colegial.

Todavia, outro fator complicava ainda mais a conjuntura educacional: o aumento da procura por vagas no ensino superior. A despeito da baixa escolarização da grande maioria da população, as reformas no nível médio que abriram a possibilidade de ingresso no nível superior para os egressos dos cursos técnicos. Num cenário de mudanças econômicas e de declínio nos processos de acumulação de capital das camadas médias, a formação em nível superior, e a busca por carreiras liberais era uma alternativa para a manutenção do status quo de jovens advindos das camadas médias da população. Para Cunha (1988), o aumento de demanda por vagas no ensino superior durante o regime militar piora uma questão que já comprometia o cenário educacional, tanto no nível médio, quanto no superior. Afirma esse autor que

\begin{abstract}
A mudança do regime político em abril de 1964 não fez retroagir a crescente procura de ensino superior. Ao contrário, a fez avançar. O crescimento da população urbana, a industrialização e a monopolização, gerando aumento das camadas médias, em termos absolutos; a redefinição do papel da mulher como trabalhadora no âmbito doméstico; a elevação dos requisitos educacionais para o preenchimento dos cargos nas burocracias públicas e privadas, foram processos que seguiram seu curso após o golpe. Ademais, eles se intensificaram pela política econômica adotada (CUNHA, 1988, p. 86-87).
\end{abstract}

O grande dilema era incrementar a economia, agradar ao grande capital que se estabelecia no país e conter as massas. Em dezembro de 1971 a promulgação da Lei 5.692 marcou uma decisão controversa para a educação brasileira, ao determinar, entre outras coisas, a formação técnica compulsória (BRASIL, 1971). 
A proposta de profissionalização para os jovens estudantes do ensino médio causou estranhamento e descontentamento entre educadores e estudiosos da educação. Após um longo período em que grande parcela da população esteve privada do acesso à escola, as demandas sociais pelo aumento da oferta começaram a pressionar o governo. A proposta de ampliação do acesso efetivada pela Lei 4.024/61 não foi suficiente para inserir a parcela da população historicamente excluída da escolarização formal. Além desse fator, a expansão econômica passou a exigir qualificação superior àquela existente, o que se constituiu como uma pressão a mais pela reforma educacional. Todavia,

\begin{abstract}
Somente, pois, quando há necessidade de redefinição na expansão econômica que implique o aparecimento ou incremento de demanda econômica de recursos humanos de vários níveis de qualificação e também quando do remanejamento das forças na estrutura do poder objetive utilizar-se da modernização como ideologia de justificação e necessite aumentar as oportunidades educacionais em determinada direção, é que as pressões da demanda social de educação começam a ser consideradas (ROMANELLI, 1991, p. 203).
\end{abstract}

Entretanto, em meio a tantas alterações legais e mudanças na perspectiva de formação dos jovens, não houve qualquer alteração nos anos seguintes à promulgação da Lei 5.692/71 no formato do Colégio Universitário da UFV. A criação de colégios universitários vigorou até 1968, quando o artigo 79, da Lei 4.024/61 foi revogado pelo artigo 19, do Decreto-Lei 464, de fevereiro de 1969 (BRASIL, 1969). A lei proibia a criação de novos colégios, mas não obrigava a extinção dos já existentes. Isso causou dúvida entre legisladores e entre as instituições. A oferta da terceira série do ciclo colegial só foi suprimida pela Lei 5.692/71, que revogou o artigo 46, da Lei 4.024/61.

Tal oferta permaneceu no COLUNI até 1981, sem que qualquer forma de profissionalização ocorresse, apesar do que preconizava a lei. Apenas a partir de 1982, o COLUNI passou a ofertar as três séries do segundo grau. O Colégio completou em 2015 cinquenta anos de existência. Atualmente tem sede própria e figura no ranking do ENEM como a melhor escola pública de ensino médio do país. Esse desempenho tem se repetido desde 2007, sendo que por seis anos consecutivos o Colégio figurou como o melhor da rede pública na avaliação do ENEM. Em 2013 foi a $12^{\mathrm{a}}$ escola mais bem classificada no ranking geral (MORENO; GUILHERME, 2014).

Assim, a compreensão do binômio elitismo e excelência na história da educação brasileira, especialmente no ensino médio do COLUNI se configuram como fundamentais para a pesquisa em curso, pois estiveram (ou estão ainda) presentes na organização do sistema educacional brasileiro. Compreender esse movimento é o que nos move.

A questão que se coloca para tal empreitada é: O COLUNI se insere no sistema educacional como uma alternativa à dualidade estrutural ou reforça essa dualidade? Para tanto, a pesquisa se desenvolveu a partir da pesquisa documental. Foram analisados documentos ${ }^{\mathrm{ii}}$ disponíveis

\begin{tabular}{l|c|c|c|c|c|c} 
(C) Rev. Educ. Perspec. & Viçosa, $M G$ & v.9 & n.3 & p.603-618 & set./dez.2018 & eISSN 2178-8359 \\
\hline
\end{tabular}


no Arquivo Central e Histórico da Universidade Federal de Viçosa e do Colégio CAp-Coluni (Colégio de Aplicação), a partir da perspectiva do materialismo histórico-dialético.

A opção metodológica pela pesquisa histórica, a partir da abordagem pelo método dialético, justifica-se por buscarmos investigar "a conexão íntima entre a forma pela qual a sociedade produz sua existência material e a instituição escolar que cria" (NOSELLA; BUFFA, 2009, p. 79). Para esses autores, "a dialética marxista consiste em algo mais específico, pois, ao relacionar estrutura e superestrutura, nega a atual sociedade, apontando para um horizonte de valores humanos que, hoje, existem apenas potencialmente, a saber a igualdade e a justiça entre os homens" (NOSELLA; BUFFA, 2009, p. 78). A compreensão das contradições nas relações materiais de produção nos levou a crer que o método escolhido seria adequado às análises que nos permitiriam entender a história do COLUNI. Neste artigo trataremos da ideia de excelência presente em correspondências e relatórios do Colégio Universitário.

\section{ELITISMO E EXCELÊNCIA: VILÃO E VIRTUDE NUMA HISTÓRIA DE DESIGUALDADE}

A medida da qualidade no COLUNI, desde sua criação e ao longo dos primeiros quinze anos, era a aprovação no vestibular da UFV e o bom desempenho dos alunos egressos nas disciplinas dos cursos de graduação. Os relatórios encontrados ${ }^{\mathrm{iii}}$ trazem sempre os dados dos alunos do Colégio referentes à aprovação no vestibular e nas disciplinas da graduação na comparação com os alunos egressos de outras instituições.

A partir dos documentos encontrados, contudo, percebe-se que a criação do COLUNI e os quinze primeiros anos de sua existência estão cercados de contradições. Por um lado há uma mobilização no cenário educacional, questionando a educação vigente à época. A escola pública de educação básica não atendia a grande maioria de crianças e jovens, o que a fazia ser conhecida como elitista e excludente. Por outro, há uma proposta de profissionalização para os jovens ainda no segundo grau (a partir de 1971), sob o argumento de que a indústria demandaria essa formação para os trabalhadores e atender aos propósitos de industrialização da nação era urgente e necessário. As poucas vagas existentes para os cursos de nível superior também aumentavam a pressão sobre o sistema educacional.

Amarílio Ferreira Jr. traz na introdução do livro "História da Educação Brasileira: da Colônia ao século XX" a afirmação de que a educação brasileira "sempre foi, a um só tempo, elitista e excludente" justificando que "até o momento, manteve-se em perfeita sintonia com o processo de desenvolvimento econômico autoritário e concentrador de renda, historicamente, imposto à sociedade brasileira" (FERREIRA JR., 2010, p. 13). O binômio elitismo e exclusão é, pois, recorrente na literatura sobre a história da educação, e não menos sobre outras questões que envolvem o campo de estudo da educação no Brasil.

\begin{tabular}{l|l|l|l|l|l|l} 
(C) Rev. Educ. Perspec. & Viçosa, $M G$ & v.9 & n.3 & p.603-618 & set./dez.2018 & eISSN 2178-8359 \\
\hline
\end{tabular}


Nesse sentido, a dualidade estrutural é tratada por Cury, quando analisa a inexistência de um sistema nacional de educação no país. Historicamente a educação foi organizada de forma dual, se constituindo como dois caminhos diversos para pessoas diversas na origem e no percurso socioeconômico. Assim, Cury (2008, p. 1191, grifos do autor) aponta o "conflito social privilégio (das elites) x direito (aberto a todos e a cada um)" como presente na legislação brasileira, em todos os momentos da história da nação.

As palavras "elitista" e "excelência" estão presentes na história do COLUNI. Em algumas correspondências o diretor admite tratar-se de um colégio de elite, em busca da excelência no desempenho dos seus alunos. Para muitos viçosenses e mesmo para alguns professores da UFV, no entanto, o Colégio sempre foi elitista e excludente, por não incorporar pobres, negros e muito menos a população da cidade.

A ideia de excelência na UFV tem raízes nos primórdios da Instituição, quando foi criada a Escola Superior de Agricultura e Veterinária (ESAV), na década de 1920. A inculcação do chamado "espírito esaviano" tem sua origem na disciplina e no rigor acadêmico com que foi criada a ESAV e no qual foram mantidos os alunos, desde os primeiros anos de sua existência (AZEVEDO, 2005).

As várias fases e crises por que passou a Instituição só fizeram fortalecer esse espírito. Nos anos 1960/1970, para fazer frente aos problemas trazidos pelos alunos de um ensino médio precário, a Instituição demandava uma formação diferenciada. A criação do Colégio Universitário veio suprir essa necessidade garantindo a excelência aos alunos egressos.

\section{A excelência e o direito à educação: farinha pouca, meu pirão primeiro...}

No cenário de precarização da educação primária (após a obrigatoriedade de matrícula no ensino primário determinada pela Lei 4.024/61), as poucas vagas existentes no ensino superior não eram suficientes no contexto das mudanças na economia que alteraram a lógica da acumulação no Brasil, levando jovens da classe média a buscar o ensino superior e das transformações econômicas demandando novo perfil para os trabalhadores. A resposta do governo para conter a demanda reprimida de jovens que ansiavam pelo ensino superior vem no formato de uma reforma que, entre outras medidas, implantou o vestibular unificado e classificatório $^{\text {iv }}$.

Nesse contexto, a existência do Colégio Universitário da UFV se justificava como unidade de formação de jovens candidatos aos cursos superiores, especialmente o curso de Agronomia, garantindo a excelência herdada da tradição esaviana. Assim, a aprovação no exame de seleção para o COLUNI era uma esperança (quase certeza) de aprovação no vestibular da UFV. 
O desempenho dos alunos egressos do COLUNI no vestibular era acompanhado de perto pela direção do colégio, e a aprovação era a medida da excelência. Em ofício endereçado ao Reitor, o Diretor elabora sucinto relato sobre os primeiros anos do Colégio (DIRETOR DO COLÉGIO UNIVERSITÁRIO, 1971). Nesse documento cita o excelente resultado no vestibular - 95\% aprovados no período 1966-1970 e também o excelente aproveitamento dos egressos do COLUNI nas disciplinas dos cursos de Agronomia e Engenharia Florestal. Destaca que no ano de 1970, a taxa de reprovação foi reduzida e que a admissão de alunos ouvintes foi uma decisão acertada, pois dos treze admitidos como ouvintes, doze foram aprovados no vestibular.

O desejo de estudar na UFV, passando antes pelo COLUNI, era expresso em cartas dirigidas à direção do Colégio, solicitando informações e, não raro, vagas. Vinham de todos os cantos do estado de Minas Gerais (Caratinga, Cambuí, Monte Carmelo, Santos Dumont, Montes Claros, Bocaiuva, Guanhães) e não poucas de outros estados do Brasil (Espírito Santo, Bahia, Mato Grosso, Rio de Janeiro).

Em outubro de 1973, o diretor encaminha um arrazoado ao Reitor, justificando a importância do Colégio Universitário para a Universidade, como preparação dos candidatos aos cursos superiores da UFV, em razão da precária qualidade da educação de $1 .^{\circ}$ e $2 .^{\circ}$ graus:

\begin{abstract}
É notório o baixo nível das turmas de $1 .{ }^{\circ}$ s anos superiores em face da má qualidade do ensino nos $1 .^{\circ}$ e $2 .^{\circ}$ graus. É assim, necessário urgentemente, a Universidade dar base a estas turmas para que o índice de reprovação não seja tão alarmante quanto o é, até que o ensino médio seja estruturado de forma a preparar, eficientemente, o aluno para a vida acadêmica, em boa hora quando a Política Nacional de Educação é aumentar o número de vagas, diminuir o número de repetentes e formar em tempo mais curto, o maior número de técnicos qualificados (DIRETOR DO COLÉGIO UNIVERSITÁRIO, 1973).
\end{abstract}

O diretor se queixa do baixo nível dos concorrentes às vagas da UFV. E cita a importância do colégio por desenvolver no aluno o "espírito esaviano", formando uma "elite, tanto no aspecto de aproveitamento como de liderança". Destaca que o aproveitamento dos egressos no vestibular da UFV supera em muito o dos alunos vindos de outras instituições - 95\% contra 52\%, em média dos cinco anos anteriores. A baixa qualidade da formação no colegial, declarada pelos membros da administração superior da UFV, recorrentemente nos documentos, justificava a manutenção do Colégio, garantia à formação de futuros graduandos mais aptos ao curso superior e ao rigor da Instituição.

Todavia, a excelência não incluía a democratização do acesso, restrito àqueles aprovados no exame de seleção. A busca por vagas para alunos ouvintes indicava uma demanda não atendida, entre outras razões, pela falta de estrutura de atendimento, problema amplamente denunciado pela direção do Colégio. A seletividade do COLUNI guardava ainda relação direta com a dualidade da educação nacional. Por isso, conseguir uma vaga no COLUNI,

\begin{tabular}{l|c|c|c|c|c|c} 
(C) Rev. Educ. Perspec. & Viçosa, $M G$ & v.9 & n.3 & p.603-618 & set./dez.2018 & eISSN 2178-8359 \\
\hline
\end{tabular}


fosse pela aprovação na seleção, ou pela admissão como aluno ouvinte, era sempre um passo à frente dos concorrentes. Farinha pouca, meu pirão primeiro...

O controle da excelência, medido pela aprovação dos alunos egressos do COLUNI no vestibular, em contraposição aos egressos de outras instituições permanece ao longo de todo o período estudado (1965-1981) .

O debate aqui apresentado diz respeito ao conceito de Elite encontrado nos documentos do Colégio. Buscamos contrapor à concepção de uma escola de elite o conceito de escola unitária de Gramsci e compreender como o COLUNI atendeu mais à reforma universitária que à Lei 5.692/71, isto é, mantendo o formato de cursinho preparatório para o Vestibular, buscou preparar a demanda (e não reprimi-la) para os cursos da UFV. E o fez de maneira exemplar. O desempenho dos seus ex-alunos no Vestibular sempre foi destaque e, mesmo depois, nos cursos de graduação, os alunos egressos do COLUNI se destacavam dos demais. E a elite se fez.

\section{Elitista ou não? Eis a questão}

A questão "elitista ou não?" se dirigida hoje à professores e dirigentes do Colégio de Aplicação CAp-COLUNI talvez cause indignação, ainda que essa indignação seja contrariada pelas estatísticas recentes que mostram que os alunos ainda vêm, em sua maioria, de escolas privadas e das camadas mais ricas da populaçãovi. O termo "elite" aparece em várias correspondências oficiais, relatórios e correspondências recebidas de terceiros, sobre o que devemos tecer algumas considerações.

A Teoria das Elites é definida por Bobbio (2010, p. 385): "Por teoria das Elites ou elitista de onde também o nome de elitismo - se entende a teoria segundo a qual em toda a sociedade existe, sempre e apenas, uma minoria que, por várias formas, é detentora do poder, em contraposição a uma maioria que dele está privada".

Segundo Bobbio, em uma sociedade democrática as elites podem ser várias e o poder será exercido sempre por uma delas, num revezamento de forças que envolve vários setores da sociedade.

O sentido do termo "elite" é definido também por Bottomore (1996, p. 236) no verbete Teoria das Elites como "[...] grupos elitistas particulares - líderes políticos, executivos de empresas (especialmente em grandes corporações), funcionários de alta hierarquia, chefes militares e intelectuais [...]". Essa definição "vincula-se ao pressuposto de que na sociedade industrial as elites são várias, dependendo do ramo de atividade a que se esteja referindo" (BOUDON; BOURRICAUD, 2007, p. 198). Para Boudon e Bourricaud, não há acordo entre os sociólogos quanto a essa definição - se elite no plural ou no singular.

\begin{tabular}{|c|c|c|c|c|c|c} 
(C) Rev. Educ. Perspec. & Viçosa, $M G$ & v.9 & n.3 & p.603-618 & set./dez.2018 & eISSN 2178-8359 \\
\hline
\end{tabular}


Em Gramsci, vamos encontrar uma vasta discussão sobre a formação dos intelectuais e o papel dessa formação na constituição das elites dirigentes e na organização da sociedade. Ele afirma que assim determinada a elite garante a manutenção da ordem estabelecida, assegurando a sobrevivência da própria classe. Nesse sentido, a formação de técnicos na UFV seria importante, pois seriam eles os "prepostos" dos empresários, representantes dessa elite:

\begin{abstract}
Se não todos os empresários, pelo menos uma elite deles deve possuir a capacidade de organizar a sociedade em geral, em todo o seu complexo organismo de serviços, até o organismo estatal, em vista da necessidade de criar as condições mais favoráveis à expansão da própria classe; ou, pelo menos, deve possuir a capacidade de escolher os "prepostos" (empregados especializados) a quem confiar esta atividade organizativa das relações gerais exteriores à empresa. Pode-se observar que os intelectuais "orgânicos" que cada nova classe cria consigo e elabora em seu desenvolvimento progressivo, são, na maioria das vezes, "especializações" de aspectos parciais da atividade primitiva do tipo social novo que a nova classe deu à luz (GRAMSCI, 2011, p. 15-16, grifos do autor).
\end{abstract}

Ao considerarmos a pluralidade das elites, cabe ressaltar que a formação dos novos dirigentes envolve o recrutamento entre outros grupos, que não os tradicionalmente no poder, aquilo que Gramsci chamaria de "a passagem de indivíduos ou mesmo de grupos mais ou menos importantes para o estrato dos intelectuais especializados" (GRAMSCI, 2011, p. 105). Para isso, os jovens desses estratos sociais, a princípio excluídos do poder, seriam formados em instituições organizadas para esse fim, por mérito, buscando em camadas não tradicionais os novos quadros. Para Agnès van Zanten as escolas francesas com esse objetivo eram

\begin{abstract}
dotadas de internatos, gratuitas ou propondo um maior número de bolsas de estudo que as universidades, estas instituições conseguiriam atrair, além dos filhos da elite, os alunos brilhantes das classes médias pouco abastadas ou do interior, favorecendo, ao mesmo tempo, uma forte adesão ao Estado e à ordem social por ele encarnada (VAN ZANTEN, 2011, p. 305).
\end{abstract}

Para a autora, essas escolas viriam a formar quadros principalmente para o alto funcionalismo público. Percebemos uma aproximação do conceito de elite (tomado aqui com o seu sentido plural) com o significado depreendido dos documentos sobre o COLUNI, encontrados e incorporados na pesquisa. A referência a uma formação de elite que se repete nesses documentos diz respeito à formação de jovens para os cursos de graduação da UFV, especialmente o curso de Agronomia, de onde sairiam para compor os quadros do Estado (no âmbito federal e estadual), no campo da pesquisa agropecuária, bem como em empresas ligadas ao agronegócio no mercado nacional e internacional. Essa destinação é confirmada entre os entrevistados (profissionais ligados a empresas de celulose, mineração, agências de fomento estaduais e professores da própria UFV) e também por outros, reconhecidos por sua formação na UFV, ligados à política nacional, em órgãos da administração pública e do executivo dos estados.

Tal distinção tem raízes históricas na fundação da ESAV e também no interesse da Universidade pela formação de técnicos para atuação no campo da pesquisa, ensino e

\begin{tabular}{l|c|c|c|c|c|c|} 
(C) Rev. Educ. Perspec. & Viçosa, $M G$ & v.9 & n.3 & p.603-618 & set./dez.2018 & eISSN 2178-8359 \\
\hline
\end{tabular}


extensão ligados às ciências agrárias. O primeiro programa de pós-graduação nessa área foi criado na UFV, em 1961, representando assim um marco na produção científica e acadêmica do Brasil (BRUCKNER, 2011).

A importância da implantação desse programa pioneiro liga-se diretamente à questão agrária brasileira, considerada nos anos 1960 como fundamento do desenvolvimento nacional. Os técnicos formados atuaram no desenvolvimento da pesquisa e também, especialmente, de políticas públicas para a agricultura, e para a economia nacional como um todo, em empresas como a Empresa Brasileira de Pesquisa Agropecuária (EMBRAPA), Associação de Crédito e Assistência Rural (ACAR), Empresa de Pesquisa Agropecuária de Minas Gerais (EPAMIG), Empresa de Assistência Técnica e Extensão Rural (EMATER), e outras congêneres, ligadas às diversas unidades da federação (algumas empresas estaduais de pesquisa agropecuária ainda existem), bem como à iniciativa privada (SCHUH, 2006).

A estreita relação da UFV com o pensamento político e econômico nacional é explicitado no pórtico de entrada da Instituição que traz um grande marco, alusivo ao cinquentenário da UFV (1926-1976), com os dizeres: "Universidade Federal de Viçosa Sempre a serviço da Pátria”. Era imprescindível manter o Colégio para garantir a excelência da UFV.

Em Ferreira Jr. e Bittar (2008, p. 336), encontramos a afirmação de que havia uma "ligação orgânica" entre capital e Estado com vias à modernização produtiva, que tinha por objetivo o aumento da capacidade técnica da burocracia do Estado, cujo objetivo era tornar concreto o slogan "Brasil Grande Potência". Para isso, as universidades colaborariam com a formação técnica, o que colocava a UFV cada vez mais "a serviço da Pátria", desempenhando o importante papel de formação de mão de obra especializada e modernização do setor agrícola.

Germano (2011, p. 113) também afirma a existência dessa relação de proximidade entre as universidades (inclusive as menores) e os quadros do regime militar, "nos escalões intermediários da administração". Esse alcance aos altos escalões do governo e da iniciativa privada pelos profissionais formados pela UFV fortalecia o argumento de que ali se formava uma elite. A existência do COLUNI justificava-se pelo fato de que preparava os futuros graduandos para a UFV, tornando-se assim, no dizer de seus diretores e defensores, um colégio de elite.

Nesse sentido, poderíamos recorrer a Gramsci (2011), na afirmação de que a formação desses intelectuais, a princípio no segundo grau (e no COLUNI, por consequência do nosso objeto) e, posteriormente, no ensino superior (na UFV), compõe um grupo hegemônico dentro de um cenário político determinado, nesse caso o regime militar. Esse grupo, preparado para uma distinção cada vez maior da massa da população, seria destinado a se diferenciar pela excelência na aprendizagem (no ensino de segundo grau e na graduação, depois na pósgraduação) e no mercado de trabalho.

\begin{tabular}{l|c|c|c|c|c|c} 
() Rev. Educ. Perspec. & Viçosa, $M G$ & v.9 & n.3 & p.603-618 & set./dez.2018 & eISSN 2178-8359 \\
\hline
\end{tabular}


Podemos inferir que a manutenção do COLUNI como instância formadora de jovens para os cursos de graduação não foi ingenuamente irrelevante, mas objetivamente permitida para que essa formação se desse nos melhores moldes possíveis naquela época, contribuindo com um projeto governamentista de desenvolvimento nacional, com especial atenção para o setor agropecuário.

Ainda que o COLUNI não fosse destinado exclusivamente para uma elite econômica e social, pois ali se encontravam algumas exceções vindas das camadas mais pobres, permeando as fissuras do sistema, era certamente direcionado à formação de uma elite agrária e burocrática, dentro do Estado brasileiro. Para os que conseguiram vencer a barreira da seleção - as fissuras - a regra era, como dito anteriormente, passar pelo COLUNI rumo a uma carreira na UFV ou em agências de fomento para a agropecuária nacional, como EMBRAPA, EPAMIG, EMATER, ACAR, além das empresas privadas do agronegócio e do grande capital, inclusive na área da produção mineral, como Gerdau, Vale do Rio Doce e outras.

Apesar de a UFV ser, na década de 1960, uma instituição do interior, sem grande alcance do ponto de vista do número de alunos e do número de cursos (apenas três quando da criação do COLUNI), ao longo do tempo passou a ter um papel importante no cenário nacional, crescente no que diz respeito à formação de técnicos qualificados para atender à demanda do setor agrário nacional, dado o número de alunos que viriam a ocupar cargos nessas empresas já citadas, que eram formados no curso de Agronomia especialmente, mas não menos na Zootecnia e na Veterinária.

Cabe destacar o percurso comum entre os entrevistados - aluno do COLUNI, aluno da graduação da UFV e docente da Universidade. Isso demonstra a escassez de qualificação à qual Germano (2011, p. 146) se refere - "a massa dos docentes era escassamente qualificada" e "faltavam recursos humanos altamente qualificados para a pesquisa científica e tecnológica, e era necessário desenvolver um grande esforço para produzi-los no país". A necessidade de desenvolver a pesquisa era premente em todos os setores da economia, e não menos no setor agropecuário.

O COLUNI privilegiava o topo da pirâmide social, abrigando em seus quadros os filhos das camadas mais ricas da população - os grandes proprietários de terra, os fazendeiros - ainda que permeado eventualmente por um ou outro representante das classes subalternas, como filhos de lavadeiras, costureiras ou outros mais insistentes, que precisavam trabalhar na escola para garantir o próprio sustento. A despeito da intenção da Lei 4.024/61 de vulgarizar a formação na educação básica, de fato a realidade concreta impunha uma condição que impedia o avanço daqueles que dependiam do trabalho precoce para a garantia da propria subsistência e da dos seus. A perspectiva da excelência, portanto, passava (e ainda passa) pela seleção dos mais aptos.

\begin{tabular}{|c|c|c|c|c|c|c} 
(C) Rev. Educ. Perspec. & Viçosa, $M G$ & v.9 & n.3 & p.603-618 & set./dez.2018 & eISSN 2178-8359 \\
\hline
\end{tabular}


Florestan Fernandes (1966, p. 20) afirmava, nos anos 1960, que "as oportunidades educacionais assumem, em todos os ramos do ensino extra-primário, caráter seletivo predominantemente extra-educacional" Não era apenas a avaliação da aprendizagem que excluía o estudante, mas sua condição socioeconômica o impedia de permanecer na escola. Nos anos 1960 e 1970 essa exclusão persistiu, especialmente no ensino de grau médio, prioritariamente ofertado pela rede privada, inviável para a maioria dos jovens pelo alto custo. E acrescia-se a isso o fato de nem todos os municípios contarem com escolas secundárias, o que inviabilizava a continuidade dos estudos para os jovens ali residentes (FERNANDES, 1966).

Menos de 10\% dos estudantes que ingressavam no ensino primário em 1961 tinham acesso ao ensino superior (OEI, 2015). E, desses, a maioria só o tinha pelas instituições privadas. O ensino superior público era reservado aos filhos das camadas mais ricas da população, no Brasil e na UFV.

Havia, naquele momento de reestruturação do ensino universitário, uma discussão intensa sobre a forma de ingresso na universidade, tanto internamente, envolvendo as universidades e o MEC, quanto por parte dos acessores externos, inclusive aqueles vinculados ao convênio MEC-USAID. Os vários estudos discutiam, entre outras temáticas, o ingresso nos cursos superiores e as dificuldades dos alunos no cumprimento das exigências dos cursos após o ingresso. $\mathrm{O}$ vestibular unificado era uma opção, mas que apresentava riscos. Havia também uma proposta de redução do conteúdo do vestibular às disciplinas Português, Matemática e uma língua estrangeira, o que também era fator complicador. Segundo Cunha, na avaliação do Relatório da Equipe de Assessoria ao Planejamento do Ensino Superior,

\footnotetext{
Medidas como essas (vestibular unificado e redução de conteúdo) levariam, muito provavelmente, à entrada de alunos mais fracos nos cursos superiores. Para corrigir esse efeito indesejável, os brasileiros recomendaram a elevação do rigor na avaliação do rendimento dos alunos dentro da universidade, acabando com as "aprovações quase automáticas que se fazem em certas escolas superiores, uma vez transposto o obstáculo vestibular" (p. 151). [...] Em suma, a proposta dos brasileiros consistia em rebaixar a barreira do vestibular e transferir para dentro da universidade - diluído - o mecanismo de seleção (CUNHA, 1988, p. 198).
}

Essa preocupação com a qualidade no ensino superior era observada na UFV, traduzida no argumento frequente para a manutenção do COLUNI: o baixo rendimento dos alunos da graduação. Os alunos vindos do Colégio Universitário superavam o rendimento dos egressos de outras instituições, o que, provavelmente, economizava esforços e recursos da Instituição. As reprovações oneravam o orçamento minguado e o COLUNI era a esperança de que a qualidade, tão cara à Instituição, fosse mantida.

O inconveniente de uma escola de elite é o seu reduzido alcance, e não a forma como ela é organizada. Nem sempre é possível passar pela fissura.

\begin{tabular}{l|c|c|c|c|c|c} 
(C) Rev. Educ. Perspec. & Viçosa, $M G$ & v.9 & n.3 & p.603-618 & set./dez.2018 & eISSN 2178-8359 \\
\hline
\end{tabular}




\section{CONSIDERAÇÕES FINAIS}

O caráter desigual da sociedade brasileira é o caráter da sua educação. O grande contingente de excluídos dos processos educativos formais permaneceu excluído da educação modernizadora dos governos militares. A pretensa democratização dos governos populistas que antecedeu o Golpe de 1964 foi abortada, mantendo o caráter privatista da educação.

Nesse contexto, o conceito de elite permite compreender como a educação brasileira se constituiu historicamente, convertendo-se num processo de segmentação da sociedade entre quem pensa e quem executa, conforme os moldes do capital. A superação da escola que temos se fará com a Escola Unitária: "escola única inicial de cultura geral, humanista, formativa, que equilibre de modo justo o desenvolvimento da capacidade de trabalhar manualmente (tecnicamente, industrialmente) e o desenvolvimento das capacidades de trabalho intelectual" (GRAMSCI, 2011, p. 33). A excelência proclamada não se constituia, no momento da criação do COLUNI, e nem se constitui hoje, um direito pleno e para todos. Sendo assim, faz com que as instituições que a mantém e os estudantes que a desfrutam privilegiados, perpetuando uma ilha de exclusão.

A partir dos estudos realizados percebemos uma sintonia entre a existência do COLUNI e a dualidade estrutural do ensino de nível médio no Brasil. Outros estudos são necessários a fim de aprofundar outras questões, mas podemos vislumbrar a questão da excelência como a marca de nascença dessa instituição.

Aprovar alunos para o ensino superior, no momento em que a expansão da escolarização trazia alunos das camadas mais pobres da população para dentro da Universidade tornou-se um desafio urgente para o Colégio. O COLUNI era, portanto, naquele momento, a alternativa de garantia de um público seleto e já conformado aos padrões da UFV.

Atualmente, entre os quadros da administração contam-se muitos ex-alunos, o que a Instituição exibe com orgulho. A ideia da excelência ainda prevalece no Colégio, hoje Colégio de Aplicação, especialmente reforçada pelos indicadores oficiais, especialmente o ENEM. O sucesso dos alunos nessa avaliação é anunciado como a marca da excelência histórica, remontando sempre ao passado de glória do COLUNI.

Resta compreender em que medida (e se) esse modelo se adequava à dualidade da educação brasileira. Os sinais de resistência às mudanças impostas pelo governo, as dificuldades estruturais e seus reflexos no ensino e outros problemas enfrentados nesse primeiro período (1965-1981) são também questões a serem respondidas. Como o fio de Ariadne, buscamos respostas e as perguntas se multiplicam. O rio da história não para.

\begin{tabular}{l|c|c|c|c|c|c} 
(C) Rev. Educ. Perspec. & Viçosa, $M G$ & v.9 & n.3 & p.603-618 & set./dez.2018 & eISSN 2178-8359 \\
\hline
\end{tabular}




\section{REFERÊNCIAS}

AZEVEDO, Denílson Santos de. Melhoramento do Homem, do Animal e da Semente: O Projeto Político Pedagógico da ESAV (1920-1948): Organização e Funcionamento. 2005. 220 f. Tese (Doutorado em Educação). Programa de Pós-Graduação da Faculdade de Educação da Universidade de São Paulo. São Paulo, SP, 2005.

BOBBIO, Norberto. Teoria das Elites. In: BOBBIO, Norberto; MATTEUCCI, Nicola; PASQUINO, Gianfranco (Orgs.). Dicionário de Política. 13. ed. Brasília: Editora UnB, v. 1, 2010. P. 385-391.

BOTTOMORE, Tom. Elite, teoria das. In: OUTHWAITE, William; BOTTOMORE, Tom (Org.). Dicionário do pensamento social do Século XX. Tradução de Renato Lessa e Wanderley Guilherme dos Santos. Rio de Janeiro: Jorge Zahar, 1996. p. 201-202.

BOUDON, Raymond; BOURRICAUD, François. Dicionário Crítico de Sociologia. 2. ed.. São Paulo: Ática, 2007.

BRASIL. Decreto-Lei n. ${ }^{\circ}$ 464, de 11 de fevereiro de 1969. Estabelece normas complementares à Lei 5.540, de 28 de novembro de 1968, e dá outras providências. Câmara dos Deputados: Brasília, DF, 1969. Disponível em: http://www2.camara.leg.br/legin/fed/declei/1960-1969/decreto-lei-464-11-fevereiro-1969376438-publicacaooriginal-1-pe.html. Acesso em: 21 set. 2015.

BRASIL. Lei n. ${ }^{\circ}$ 4.024, de 20 de dezembro de 1961. Fixa as Diretrizes e Bases da Educação Nacional. Brasília, DF, 1962. Disponível em: http://www.planalto.gov.br/ccivil_03/leis/14024.htm. Acesso em: 13 out. 2013

BRASIL. Lei n. ${ }^{\circ}$ 5.692, de 11 de agosto de 1971. Fixa as Diretrizes e Bases para o ensino de $1^{\mathbf{0}}$ e $2^{\mathbf{0}}$ graus e dá outras providências. Câmara dos Deputados: Brasília, DF, 1971. Disponível em: http://www2.camara.leg.br/legin/fed/lei/1970-1979/lei-5692-11-agosto-1971357752-publicacaooriginal-1-pl.html. Acesso em: 04 jul. 2014.

BRUCKNER, Cláudio Horst. Pós-Graduação em Ciências Agrárias: 50 anos de História. Rev. Ceres, Viçosa, MG, v. 58, n. 3, p. 1, maio/jun. 2011. Disponível em: http://www.scielo.br/scielo.php?pid=S0034-737X2011000300002\&script=sci_arttext. Acesso em: 03 fev. 2016.

CUNHA, Luiz Antônio. A Universidade Reformanda: o golpe de 1964 e a modernização do ensino superior. Rio de Janeiro: Francisco Alves, 1988.

CURY, Carlos Roberto Jamil. Sistema Nacional de Educação: desafio para uma educação igualitária e federativa. Educ. Soc., Campinas, v. 29, n. 105, p. 1187-1209, set./dez. 2008. Disponível em: http://www.scielo.br/pdf/es/v29n105/v29n105a12.pdf. Acesso em: 15 mar. 2015. 
DIRETOR DO COLÉGIO UNIVERSITÁRIO. [Correspondência] 05 fev. 1971, Viçosa [para] Reitor da Universidade Federal de Viçosa. 3f. Repassa dados do Colégio Universitário e demonstra principais resultados alcançados. Viçosa, MG, 1971.

DIRETOR DO COLÉGIO UNIVERSITÁRIO. [Correspondência] 05 out. 1973, Viçosa [para] Reitor da Universidade Federal de Viçosa. 2f. Descreve a importância do Colégio Universitário para a Universidade Federal de Viçosa. Viçosa, MG, 1973.

FERNANDES, Florestan. Educação e sociedade no Brasil. São Paulo: Ed. da USP, 1966.

FERREIRA JR., Amarílio. História da Educação Brasileira: da Colônia ao século XX. São Carlos: EdUFSCar, 2010.

FERREIRA JR., Amarílio; BITTAR, Marisa. Educação e ideologia tecnocrática na ditadura militar. Cad. CEDES, Campinas, v. 28, n. 76, p. 333-355, dez. 2008. Disponível em: http://www.scielo.br/scielo.php?script=sci_arttext\&pid=S0101-32622008000300004 \&lng=en\&nrm=iso. Acesso em: 31 out. 2015.

FRANCO, Maria Aparecida Ciavatta Franco; BAETA, Anna Maria Bianchini. Quinze Anos de Vestibular (1968 a 1983). Apresentação. Educação e Seleção, São Paulo, n. 12, jul./dez. 1985.

GERMANO, José Willington. Estado Militar e educação no Brasil (1064-1985). 5. ed. São Paulo: Cortez, 2011.

GRAMSCI, Antônio. Cadernos do Cárcere. 6. ed. Rio de Janeiro: Civilização Brasileira, v. $2,2011$.

MORENO, Ana Carolina; GUILHERME, Paulo. Inep divulga as notas do Enem 2013 por escola. G1 - Educação. 22 dez. 2014. Disponível em:

http://g1.globo.com/educacao/noticia/2014/12/inep-divulga-notas-do-enem-2013-porescola.html. Acesso em: 23 abr. 2018.

NOSELLA, Paolo; BUFFA, Ester. Instituições Escolares: por que e como pesquisar. Campinas, SP: Editora Alínea, 2009.

OEI. Organização dos Estados Ibero-americanos. Breve evolução histórica do sistema educacional. Ministério da Educação de Brasil. 2015. Disponível em: http://www.oei.es/quipu/brasil/historia.pdf. Acesso em: 15 nov. 2015.

ROMANELLI, Otaíza de Oliveira. História da Educação no Brasil (1930/1973). 13. ed. Petrópolis: Vozes, 1991.

SCHUH, George Edward. Cooperação internacional e desenvolvimento institucional: benefícios mútuos. In: BORGES, José Marcondes; SABIONI, Gustavo Soares; MAGALHÃES, Gilson Faria Postch (Org.). A Universidade Federal de Viçosa no Século XX. 2 ed. Viçosa: Ed. UFV, 2006. P. 101-105.

\begin{tabular}{l|c|c|c|c|c|c} 
(C) Rev. Educ. Perspec. & Viçosa, $M G$ & v.9 & n.3 & p.603-618 & set./dez.2018 & eISSN 2178-8359 \\
\hline
\end{tabular}


VAN ZANTEN, Agnès. Elites (formação das). In: VAN ZANTEN, Agnès (Coord.). Dicionário de Educação. Petrópolis: Vozes, 2011. P. 304-310.

\section{NOTAS}

' Durante a pesquisa foram localizados, além do COLUNI da UFV, colégios universitários, criados sob a égide da Lei 4.024/61, nas universidades federais de Minas Gerais, Rural do Rio de Janeiro, do Maranhão, Rural de Pernambuco e do Rio Grande do Norte. Todos foram extintos ou transformados em Colégios de Aplicação após o Decreto 464/69 (BRASIL, 1969).

ii Os documentos utilizados na pesquisa foram: atas de reuniões da Congregação da Escola Superior de Agricultura da UREMG; correspondências oficiais da instituições; correspondências recebidas de terceiros; relatórios de atividades do COLUNI e da UREMG/UFV; portarias.

iii Foram encontrados relatórios referentes ao período estudado (1966-1981), à exceção dos anos de 1973, 1976, 1977, 1978, 1980 e 1981.

iv Até 1968, a seleção era feita a partir de avaliações que estabeleciam a nota mínima igual ou superior a cinco, ficando a matrícula restrita à existência de vagas. Essa condição abria o precedente legal da aprovação para a exigência, na justiça, do direito à matrícula, o que levou ao vestibular classificatório (FRANCO; BAETA, 1985). ${ }^{v}$ Em 1982 o COLUNI passou a ofertar as três séries do segundo grau.

${ }^{\text {vi }}$ A série histórica de 2009 a 2015 mostra que não mais que 15\% dos estudantes matriculados no COLUNI têm renda familiar de até dois salários mínimos mensais. Em torno de $40 \%$ tem renda familiar acima de cinco salários mínimos. Nenhum deles trabalha. Não há estudantes com necessidades especiais no Colégio. Uma média de $35 \%$ deles tem pais com ensino superior completo.

\section{Sobre a autora}

'Joana D'Arc Germano Hollerbach - Professora do Departamento de Educação da UFV, área de gestão. E-mail: joana.germano@ufv.br - ORCID: https://orcid.org/0000-0002-3931-7836 